\title{
"MAS EU TENHO UMA COISA MÁ PARA CONTAR": CRIME E CASTIGO NO CONTO “OVERBOOKING”, DE LÍDIA JORGE
}

\author{
Ágata Cristina da Silva Oliveira ${ }^{1}$
}

\begin{abstract}
RESUMO: O presente trabalho possui como objetivo central analisar o conto "Overbooking", presente na obra $O$ amor em Lobito Bay, da autora portuguesa Lídia Jorge, tomando como arcabouço teórico a estética da crueldade (ROSSET, 1989), a presença do fantástico na literatura (TODOROV, 2003) e os elementos presentes no gênero conto (CORTÁZAR, 2006; PIGLIA, 2004). Partindo de uma análise do discurso do sujeito narrante do texto, questiona-se os efeitos da memória sobre os acontecimentos, assim como a capacidade da linguagem de subverter a retratação do passado. Para tal, utiliza-se ainda textos de apoio como Tempo Passado (SARLO, 2007), Problemas da Poética de Dostoiévski (BAKHTIN, 2002) e A Dominação Masculina (BOURDIEU, 2002).
\end{abstract}

PALAVRAS-CHAVE: Literatura portuguesa contemporânea. Literatura fantástica. Estética da crueldade. Literatura e memória.

Os livros escritos no século $X X$, aqueles de que mais gostamos e com os quais nos formámos, são fábulas criadas para erguerem, de mil maneiras, a demonstração de que não passamos de figuras bizarras, contendo num só recipiente a raiz de todos os bens e de todos os males, incluindo o acto de julgar e a nomeação das coisas, o que ainda por cima só a nós pertence.

Lídia Jorge, Para um leitor ignorado.

Embora tenha conquistado seu espaço na literatura portuguesa contemporânea principalmente por meio de romances como O Dia dos Prodígios (1980), O Cais das Merendas (1982) e A Costa dos Murmúrios (1988), a genialidade de Lídia Jorge está presente também na forma breve dos contos. A autora que possui volumes como Marido e outros contos (1997), O belo adormecido (2004) e Praça de Londres (2008) publicou, em 2016, um livro de contos intitulado $O$ amor em Lobito Bay.

Os contos reunidos nesse título, possuem, como um dos pontos de contato, espaços situados fora de Portugal, passando por territórios como a Angola em meio aos conflitos internos do período pós-colonial e os caminhos percorridos pela literatura de Faulkner em New Orleans. As personagens se encontram em situações em que passam de um estado de tranquilidade à ferocidade ao receberem uma revelação demolidora, ao terem que testar seus

1 Mestre em Letras: Estudos Literários pela Universidade Federal de Viçosa/MG, Email: agatacristinasilvaoliveira@yahoo.com.br 
próprios limites, ao passarem por uma decepção que se transforma em sabedoria. Segundo Cortázar,

um conto, em última análise, se move nesse plano do homem onde a vida e a expressão escrita dessa vida travam uma batalha fraternal, se me for permitido o termo; e o resultado dessa batalha é o próprio conto, uma síntese viva ao mesmo tempo que uma vida sintetizada, algo assim como um tremor de água dentro de um cristal, uma fugacidade numa permanência. (2006, p. 150)

Há, em todos os contos deste livro, a memória de um momento em que o homem se confronta com o desconcerto do mundo. Em "O amor em Lobito Bay", conto que dá título ao livro, um professor conta aos seus alunos como sua família se reúne num complô para evitar que ele mate uma andorinha e coma seu coração a fim de se tornar o mais rápido corredor. A família tenta proteger a criança de executar um ato que o marcaria para sempre, mas não consegue protegê-lo de presenciar os horrores da violência da guerra. Entretanto, é a atuação familiar que lhe fica marcada:

Mas a verdade é que também não puderam evitar a imagem fundadora
da minha vida, disse o professor. Aquela que eu imagino que tenha
acontecido ao longo de uma noite em que uma família inteira se coligou
para evitar que o segundo filho mais novo, o segundo irmão menor,
pegasse num cutelo e matasse por seu próprio punho o corpo de uma
andorinha. Quantos homens, condenados a morrer no futuro às mãos de
quem iria iniciar-se no crime de sangue não terão sido poupados a partir
dessa noite de armistício, acontecida em Lobito Bay? (JORGE, 2016, p.
28)

Em "O templo do esplendor" a inocência infantil aparece na reminiscência do "tempo das grandes casas para três pessoas, o tempo das criadas, o tempo da água não canalizada, o tempo de uma lâmpada só a balouçar do tecto, o tempo dos jardins domésticos com lagos e peixes vermelhos, o tempo dos professores de Latim como era o meu pai" (Ibidem, p. 51-2). Nesse tempo, vê-se a busca de uma menina por justiça: para ela não parece certo que sua mãe possua lenços bordados e o pai não. A criança tenta corrigir isso bordando um lenço para o pai.

A inocência infantil também é destaque em "Imitação do Êxodo". Douglas, um jovem professor, leva seus alunos ao parque a fim de que encenem uma guerra. Juliana, "uma menina normalmente bem comportada" (Ibidem, p. 70-1) só consegue falar sobre 'o relógio do seu bisavô estar no parque'. O cuco, pássaro que só muito depois é compreendido como o tal relógio, acaba por se tornar 
objeto de atenção de todos os alunos que, no dia seguinte, o representam no papel ao invés do exercício feito no parque, como era a intenção dos professores.

Em "Passagem para Marion" acompanhamos o deslumbramento pelo acaso que uma mulher sente, após ter visto um rapaz brincando com seu cão durante a tarde no parque, e reencontrá-lo na casa do embaixador onde vai jantar e passa a conhecer seu drama: após pressupor que lhe seria pedido que desse um fim no seu cão como trabalho de conclusão do mestrado, ao modelo do que ouvira falar que acontecia no Japão, Mário decide abandonar o MBA. Consequentemente, seus pais se recusam a enviar dinheiro para que ele leve 0 cão para casa ao retornar ao seu país e o jovem se recusa a retornar sem o cão.

O conto "Um rio chamado mulher" homenageia Faulkner ao nos apresentar a uma narradora que vai à New Orleans refazer o caminho percorrido pelas personagens de "The Old Man". Para tal, a narradora serve-se do serviço de guia de Barbara, figura que ela descobre posteriormente ser mais lendária e celebrada na cidade do que o próprio escritor homenageado: Barbara era "um património da cidade New Orleans" (Ibidem, p. 109).

A narrativa de "Novo mundo" de forma irônica e bem humorada, traz a história de uma catedral cujo telhado precisa de consertos. A fim de incentivar seus fiéis a doarem o dinheiro necessário para pôr o telhado no lugar, decide-se que toda pessoa que fizer um donativo, terá seu nome gravado no telhado. Entretanto, uma alta doação secreta deixa o padre Adam Friedman intrigado: como alguém poderia doar tanto sem declarar seu nome? Como proceder então? Que nome colocar no telhado? Sua busca pela identidade do doador o leva a conclusões irrealistas acerca da origem do dinheiro.

Em "Dama polaca voando em limusine preta" acompanha-se os momentos de agonia da personagem que, de partida para o aeroporto se vê presa em uma limusine com um motorista que não para de afirmar o quanto ela se parece com sua falecida mulher.

O conto "O poeta inglês" apresenta um pequeno grupo de escritores de nacionalidades diferentes que, ao se apresentarem em uma sessão literária, notam como o poeta inglês ganha destaque e é celebrado, fazendo com que todos os outros se sintam inferiores. A inveja é percebida pela mista de preocupação e secreta alegria que surge com o sumiço do poeta. 
O conto que se pretende analisar neste artigo, contudo, tem como título "Overbooking". Desde o início da trama com ecos de Crime e Castigo, o narrador deixa claro que o relato a ser feito não será de uma história amena: a aldeia de Kimbalina, espaço da ação narrada, é um lugar onde "os homens são bons, vão à missa aos domingos e estão inscritos na lista do trabalho comunitário, que o fazem cumprindo cada um o seu turno, mas eu tenho uma coisa má para contar" (JORGE, 2016, p. 29). O discurso do narrador, segundo percebe-se ao longo do conto "se torce na presença ou ao pressentir a palavra, a resposta ou a objeção do outro" (BAKHTIN, 2002, p. 197).

Há, em "Overbooking", uma memória que precisa ser relatada a fim de que a personagem possa passar pela catarse. Há um fantasma que precisa ser libertado e, a única forma para que essa libertação aconteça é mediante a revelação de um crime cometido no passado ou da "coisa má" que há para ser contada. Antes de começar a contar o evento propriamente dito que se configura nessa "coisa má", o narrador, embora tenha participado da ação a ser relatada, tenta produzir um efeito de distanciamento do sujeito narrado utilizando o discurso em terceira pessoa. Ele principia por apresentar o espaço no qual a história ocorre:

A vila fica a três quilômetros da cidade, pode-se dizer mesmo que a vila já é a cidade, de tal forma as casas da periferia encurtam a distância entre uma zona e a outra. E por isso temos a cantina, supermercado, dispensário para tuberculose e para a AIDS, temos cabeleireiro unissexo, e lojas de roupa e de sapatos, e uma pensão à beira da estrada, e mesmo assim eu tenho uma coisa má para contar. (Ibidem, p. 30)

E apresenta a distância temporal que há entre ele, enquanto sujeito narrante do rapaz que ele fora, o sujeito que há de ser narrado:

Não estava a representação da Missão nem estava o motel que leva o meu nome, nem a luz eléctrica que ilumina a aldeia, a cidade e a vila, formando uma teia de luzes, captadas pelo satélite, que as mostra no Google Maps como se fosse uma estrela, e mesmo assim, eu tenho uma coisa má para contar. (Ibidem, p. 31)

As informações espaciotemporais terão ainda uma função de apresentação do universo mimético do conto, elemento fundamental numa narrativa que traz o fantástico para seu texto. Segundo Roas, "afirmar a "verdade" do mundo representando é (...) um recurso fundamental para conseguir 
convencer o leitor da "verdade" do fenômeno fantástico" (2013, p. 61). Quanto mais informações palpáveis são fornecidas, mais envolvido com o elemento fantástico do texto fica o leitor.

O narrador, posteriormente apresentado como Francisco de Kimbalina, utiliza a aparição fantasmagórica, o elemento fantástico do texto, para começar sua confissão acerca da coisa má:

De noite, antes de se chegar à curva, desde há um tempo para cá, começou a surgir um carro com os dois faróis nos mínimos, um carro que avança devagar e, antes de se cruzar contigo, pára. Dele sai uma mulher vestida de azul que vem pela estrada ao teu encontro. Se tu não paras, ela sobe para cima do teu carro e voa sobre ele até chegares à vila. Se paras, ela vem andando até junto de ti, e quando está próxima, entra-te pelo peito, e desaparece. Desparece dentro do teu peito, e tu não há vês mais. (Ibidem, p. 31)

O que é surpreendente no aparecimento dessa mulher no meio da estrada, no entanto, é o fato de que ela não faz nada daquilo que se espera de um fantasma2: "a mulher que dele sai, não olha para ti, não te diz nada, não te ataca, apenas aparece, persegue-te e depois desaparece em ti” (Ibidem, p. 32), "ela vem ao teu encontro, e persegue-te, voando por cima do teu carro, ou vem ao teu encontro até encontrar o teu peito e a seguir desaparece, deixando um homem imóvel pregado ao chão, por muito tempo" (p. 46).

Esta aparição fantasmagórica é a história que se encontrará na superfície do texto: se "um conto sempre conta duas histórias" (PIGLIA, 2004, p.89), esta será a primeira a saltar aos olhos do leitor. A dubiedade do discurso do narrador mantém o caráter fantástico da narrativa do princípio à conclusão. De acordo com Todorov, quando confrontado com elementos fantásticos no texto,

o leitor se vê obrigado a escolher entre duas soluções: ou reduzir esse fenômeno a causas conhecidas, à ordem normal, qualificando de imaginários os fatos insólitos; ou então admitir a existência do

2 ROAS, 2013, p. 65: "Tentar descrever o que é, por definição, indescritível supõe o emprego de uma "retórica do indizível" (Bellemin-Nöel, 1971), um maquinismo textual que permite a irrupção do impossível no mundo ficcional. Trata-se de um conjunto de marcas textuais que assinala a excepcionalidade do representado. Estratégias discursivas (e, também, temáticas) que Bozzeto (1998, p. 176) denomina "operadores de confusão" e que intensificam a incerteza frente à percepção do fenômeno impossível: metáforas, sinédoques, comparações, paralelismos, analogias, antíteses, oximoros, neologismos e expressões ambíguas do tipo "pareceu-me ver", "acho que vi", "era como se", bem como a utilização reiterada de adjetivos fortemente conotados, como "sinistro", "fantasmagórico", "terrífico", "incrível" e outros desse mesmo campo semântico. É o que Mellier (2000, p. 42) chama "o fantástico da indeterminação": a escrita e os procedimentos narrativos tornam ambíguas as notações do texto mediante a imprecisão expressiva. Isso intensifica a percepção do fenômeno fantástico como algo impossível. 
sobrenatural e portanto inserir uma modificação no conjunto das representações que conformam sua imagem de mundo. $O$ fantástico dura o tempo dessa incerteza; assim que o leitor opta por uma ou outra das soluções, desliza para o estranho ou para o maravilhoso (2003, p. 241).

Na sequência, o narrador conta sobre como começa a história do aparecimento dessa figura fantasmagórica e o seu envolvimento na história: "Não quero fazer jogo de palavras, mas a coisa má começou por uma coisa boa. A coisa boa era o percurso que a irmã Alberta, a enfermeira da Missão, fazia entre a cidade e o interior, passando pela vila e depois pela cidade onde morávamos" (lbidem, p. 32). Esta irmã Alberta chamada algumas vezes no conto de irmã enfermeira, além de cuidar de doentes costumava dar carona às pessoas da aldeia em seu Renault 4L como pode-se conferir no trecho:

\begin{abstract}
Assim que a irmã via alguém na berma da estrada, muito rota, muito precária, ela parava. Abria a porta e levava consigo mulheres com latas de água que tinham de segurar as pernas para não molharem os estofos da 4L. Transportava homens com bordões que saíam pelas janelas, outros que levavam ao colo um porco, uma cabra, muitas vezes, sacos grandes que não cabiam no interior e vinham pendurados por fora dos vidros, fazendo da $4 \mathrm{~L}$ uma espécie de besta automóvel carregada de volumes redondos. Havia quem Ihe chamasse Alberta Chvaitza por causa das histórias que se contavam sobre os feitos ocorridos mais a norte, na localidade de Lambaréné. [...] A irmã Alberta sempre dizia, com jeito vai, assim Deus queira, assim queira a Virgem Nossa Senhora, Mãe de Nosso Senhor Cristo. (Ibidem, p. 33)
\end{abstract}

Encontra-se então, encerrada na história à superfície, a história secreta presente no conto de Lídia Jorge: é a memória relatada pelo narrador que será a "chave do conto e suas variantes" (PIGLIA, 2004, p. 91). Encaixada à narrativa fantástica está uma narrativa outra que traz para o texto a contemporaneidade da estética da crueldade. A história que vai sendo contada circunscreve o mal-estar constante em que se encontra a pós-modernidade. Não há essencialização da violência: o que encontramos é a realidade dolorosa. Segundo Renato Cordeiro Gomes:

Buscar representar esse mundo é lidar com uma impossibilidade, fazendo dela o próprio objeto da narrativa, colocando em pauta a linguagem que pretende colar-se tautologicamente a essa realidade e revela a própria artificialidade da literatura. Talvez só assim seja possível lidar com a realidade inelutável, com a sua natureza dolorosa e trágica, só possível de ser expressa por algo que lhe é exterior, a linguagem, o discurso, que para perceber a crueldade necessita de distância, de um deslocamento estratégico (2004, p. 153). 
Além da generosidade e presteza da irmã, a sua aparentemente constante calma é enfatizada pelo eu narrante: "Nunca a irmã enfermeira dizia que não, ou se enfurecia, ou praguejava. Ela não dizia cabrão ou porra, não dizia merda, não dizia esse filho da puta" (Ibidem, p. 34).

Apesar de todas as qualidades descritas nos trechos acima, é a irmã Alberta quem irá sofrer a "coisa má" da qual fala o narrador. Após um jogo de futebol em que o time dos Kimbin, do qual fazia parte o narrador, ter ganhado de 9 a 2 do time dos Fumega e, de após isto, terem se deleitado com as mangas das árvores próximo ao campo no qual jogaram, os rapazes pediram carona à irmã:

\footnotetext{
Um dia éramos catorze, a maior parte de nós, já rapazes quase homens, de assentos estreitos mas ombros largos, a irmã Alberta vinha do interior, tinha passado pela aldeia, e ia na direcção da cidade, Nós também, e pedimos-Ihe boleia. É a propósito dessa boleia que eu tenho para contar uma coisa má. (Ibidem, p. 34)
}

A irmã, que era conhecida por nunca negar um pedido de boleia se vê obrigada a usar a negativa com os rapazes por uma questão lógica: "Uf, meninos! Desta vez não pode ser. Catorze para uma carrinha de cinco lugares? Vá lá, que tenho pressa, decidam quem vai de $4 \mathrm{~L}$ e quem vai a pé" (Ibidem, p. 35). A lógica, porém, não é considerada pelos rapazes. Todos queriam entrar no carro, mesmo que isto fosse impossível.

Além do efeito de distanciamento dado pelo eu narrante com o uso da terceira pessoa, observa-se outra estratégia discursiva utilizada: a invisibilização do sujeito conferida pela sua inserção em um grupo, numa coletividade. Pode-se notar isto em trechos como "Mas nós éramos catorze e tínhamos acabado de obter uma vitória em campo. Nove golos contra dois, uma desforra nos da cidade, os Fumega, como não havia memória. Nós, os Kimbin" (Ibidem, p. 35) e "Ao todo, catorze, tínhamos comido as mangas descascadas com três facas que três de nós sempre traziam no bolso, mesmo quando estávamos em campo" (Ibidem, p. 36). São os catorze que obtiveram a vitória, os catorze pretendiam dar uma desforra nos da cidade, os catorze haviam comido mangas e os catorze iriam cometer um crime.

Há um elemento, que desde o princípio do conto irá gerar tensão e preparar o interlocutor para o que há de ser narrado: a expressão "eu tenho uma coisa má para contar" irá aparecer persistentemente no texto. "É uma intensidade 
que se exerce na maneira pela qual o autor nos vai aproximando lentamente do que conta. Ainda estamos muito longe de saber o que vai ocorrer no conto, e, entretanto, não nos podemos subtrair à sua atmosfera" (CORTÁZAR,2006, p. 158).

A tentativa de fazer com que um veículo para cinco pessoas transportasse quinze persiste por um bom tempo:

Treze rapazotes, e um rapazinho, todos a querermos entrar na carrinha. A irmã Alberta sentada ao volante, a assistir, a rir, a esperar que a realidade demonstrasse que não havia possibilidade de acomodar catorze pessoas num espaço concebido para cinco, quando muito sete, se se abatesse o banco traseiro. Virgem Santa, estão a querer o impossível, dizia a irmã enfermeira e sorria, sorria, muito mais dentes que olhos, os olhos atrás dos óculos de sol. [...] Até que a irmã perguntou - "Vocês querem que eu saia?" (Ibidem, p. 36)

A irmã sai do veículo para que os rapazes possam tomar consciência do fato de que é impossível colocar dentro daquele espaço todos o time dos Kimbin: "Sempre a rir, a irmã saiu, pôs as mãos na cintura, e ficou a olhar, à espera que a realidade demonstrasse o que a alegria de termos vencido, por nove dois, não deixava admitir" (Ibidem, p. 37). A sua serenidade, contudo, não os leva à reflexão. Antes, sua calma começa a causar a exasperação dos jovens: "O carro estava parado e o guarda redes enervou-se. Aquela gaja ria de quê? Corrigia o miúdo, porquê? O miúdo tinha razão, quem ri, ri de alguma coisa” (Ibidem, p. 37). Para aqueles rapazes, o fato de que haviam ganhado o jogo Ihes conferia uma posição de poder que deveria vir acompanhada de algum tipo de recompensa como continua a ser narrado:

Porque ria ela dos Kimbin, os Kimbin que tinham derrotado os Fumega? $\mathrm{O}$ guarda-redes exaltou-se mesmo. Ninguém para os fazer passear de camião, ninguém para Ihes dar uma taça, ninguém para thes oferecer uma Coca-Cola, ninguém para lhes dar uma bandeira, nenhum ajuntamento, nada de nada, depois de uma proeza tão grande, e agora só faltava mesmo aquela mulher, a rir deles. (Ibidem, p. 38)

Quando fica claro que a perda da consciência dos rapazes poderia resultar em um ato de violência, a irmã que permanecia fora do seu carro, ajoelha-se no mato e permanece rezando. Segundo é evidenciado na narrativa, naquele momento, a irmã havia se transformado em uma mulher comum, "sem o lenço, que já tinha perdido, era apenas uma mulher de joelhos que rezava" (Ibidem, p. 41). Ao passar do estatuto de irmã da Missão e enfermeira para uma 
mulher comum, os rapazes do Kimbin não a veem mais como sujeito que mereça ser tratado com respeito. O guarda-redes manda que ela se dispa. As vestes utilizadas pela irmã Alberta eram um símbolo de sua vida monástica. Despi-la era como dessacralizá-la ${ }^{3}$. Despi-la completamente agora era transformá-la em algo ainda menor do que uma mulher, conforme coloca no discurso do narrador: "aquilo, agora já não era nada. E era bom de ver como não era nada, como podíamos transformar, por nossas mãos, pessoas em postas de carne" (Ibidem, p. 43).

Outro importante elemento a ser destacado no conto é a simbologia da faca. A faca Sandokan é sempre citada como um objeto de poder. Bem cedo no conto fica evidente que ela será o elemento utilizado para execução da "coisa má". Afirmativas como "o treinador tinha uma faca Sandokan" (Ibidem, p. 36) repetidas mais de uma vez no conto não são gratuitas, antes nos revelam que a irmã tinha motivos para estar rezando. A faca, cuja associação pode ser também fálica, está também associada a ideia de morte, execução, vingança e sacrifício. É o portador da Sandokan quem vai incitar os demais rapazes a matar a irmã Alberta e jogar seu corpo no rio Kimba para o Gigi. Cf. CHEVALIER, 1990, p. 306.

O conto relata também a perda da inocência do "rapazinho mascote". O rapaz de doze anos, apesar de não participar ativamente no assassinato da irmã Alberta, presencia tudo:

O rapazinho mascote chorava muito alto, como um filhote de hiena desprezado. Chorava altíssimo. Era preciso acalmá-lo. O treinador encarregou-se do assunto. Se ainda não era homem não deveria ter feito parte do team. Ok? Aquilo era o seu baptizado de adulto e teria de aguentar, teria de ver tudo. E teria de se calar para a vida e para a morte. Nem que fosse preciso mostrar-Ihe a Sandokan. (Ibidem, p. 44)

Para a mascote do time, o ato de violência cometido funciona como um rito de passagem: sua participação, mesmo que silenciosa, o adequa à comunidade formada pelos rapazes que tentavam provar sua masculinidade e

3 A nudez pode abrigar distintos significados. Na cultura helenística em que o ideal de perfeição inclui o corpo, a nudez é um símbolo do belo. Na cultura cristã, embora existam registros da associação da nudez com a perfeição (como ocorre no caso do mito de Adão e Eva no paraíso) e com o sagrado, livros como Levítico e Deuteronômio que irão apresentar os códigos de comportamento para os hebreus e, posteriormente, para os cristãos, falam da nudez como algo vergonhoso e humilhante. Cf. CHEVALIER, 1990, p. 860; Naum 3:5. 
seu poder tirando a vida da irmã Alberta. Para ele era um dever afirmar a sua virilidade:

\begin{abstract}
$\mathrm{Na}$ medida em que ele tem, como sujeito, de fato, um coletivo - a linhagem ou a casa -, que está, por sua vez, submetido às exigências imanentes à ordem simbólica, o ponto de honra se mostra, na realidade, como um ideal, ou melhor, como um sistema de exigências que está votado a se tornar, em mais de um caso inacessível. A virilidade, entendida como capacidade reprodutiva, sexual e social, mas também como aptidão ao combate e ao exercício da violência (sobretudo em caso de vingança) é, acima de tudo, uma carga. [...] Como a honra - ou a vergonha, seu reverso, que, como sabemos, à diferença da culpa, é experimentada diante dos outros -, a virilidade tem que ser validada por outros homens, em sua verdade de violência real ou potencial, e atestada pelo reconhecimento de fazer parte de um grupo de "verdadeiros homens" (BORDIEU, 2002, p. 64)
\end{abstract}

Ao contrário do que se possa esperar, não há qualquer arrependimento posterior ao crime cometido. Possivelmente por, à semelhança de Raskólnikov que acreditava que manteria a sanidade e não teria problemas de consciência ao praticar o atentado que, como dizia a si mesmo, "não era um crime" (DOSTOIÉVSKI, 2002, p. 81), os rapazes acreditarem que aquilo que haviam feito não era um crime. $O$ ato é visto como uma tomada de poder, o que fica evidenciado quando o narrador diz que "era um perigo um rapazinho daquela idade participar naquela cena de glória" (Ibidem, p. 44). Havia o medo da denúncia, mas para eles aquilo era uma "cena de glória". O narrador ainda diz:

Mas nessa noite, neste hotel vazio, no meio do nada, [...] na qualidade de overbooked de um voo que partiu [...] achei que era o momento para falar daquele dia em que os Kimbin ganharam aos Fumega, em que pedimos uma boleia para catorze, e depois fizemos de uma mulher uma bola com golpes vermelhos, e depois a atirámos ao rio, chamando o Gigi. E a seguir, embriagados pelo nosso poder, corremos até à cidade, entrámos num bairro cantando, e desfizemos a reputação dos Fumega. (Ibidem, p. 47-8)

O silêncio sobre o crime cometido é mantido por mais de vinte anos. É o medo de uma aparição e não o arrependimento que irá fazer com que o narrador saia do seu estado de tranquilidade e da estabilidade financeira e boa vida conquistadas. $O$ medo de que esta presença fantasmagórica continue a o seguir ao abandonar o lugar em que vive. Segundo Chauí, "temos medo dos vivos e dos mortos. Dos subterrâneos infernais de onde sobem espectros rondando a festa imerecida" (CHAUI, 1987, p. 38). O espectro vai acompanhar esse narrador que se rotula "homem bom" e fazer com que sinta que a única saída é a confissão: 
Agora eu tenho tudo, tenho três motéis que recebem o meu nome, tenho pessoal que me respeita, ando por toda a parte, visito grandes cidades por causa dos motéis, apanho aviões, falo com gente, sou um homem bom e, no entanto, tenho para contar esta coisa má. Esta coisa má quer sobretudo ser contada quando estou longe do lugar, quer ser contada a desconhecidos, uma tentação de contar. A quem contar? (Ibidem, p. 47)

Apesar do medo de que o rapaz mais novo contasse o que acontecera naquele dia, é justamente o responsável pela incitação quem o faz. "De tal modo que pensamos que ele iria ser o elo frágil, que em breve iria contar o que vira e aquilo de que participara. Mas não, pelo contrário" (Ibidem, p. 45). A identidade do narrador é revelada pela intervenção de um interlocutor que irá aparecer como um espectro para o leitor do conto. As marcas dessa pessoa que ouve e pergunta, aparecem quando as partes mais duras da confissão de Francisco de Kimbalina são expostas. Esse interlocutor não se deixa enganar pelo discurso da memória: segundo Sarlo, "o discurso da memória, transformado em testemunho, tem a ambição da autodefesa; quer persuadir o interlocutor presente e assegurar-se uma posição no futuro; justamente por isso também é atribuído a ele um efeito reparador da subjetividade" (2007, p. 51). É esse interlocutor que não se deixará seduzir pela repetição de falas como "não sou só um homem bom, sou também um homem honrado" (Ibidem, p. 48) e perceberá que há no discurso do narrador uma intenção de fazer com que se acredite que naquela situação ele era a mascote:

\begin{abstract}
Não, isso não confirmo. Nunca foi minha ideia esconder-me atrás da figura da mascote, nunca insinuei que eu era ele. O rapazinho foi a única figura que se salvou, naquele dia. Não só sofreu com o momento, como nunca contou o que se passou. Eu poderia dizer que eu era ele, e assim o meu destino ficaria mais leve. Ser aquele que soluçou durante toda a tarde, ficar-me-ia bem, mas não, não foi assim, eu não fui inocente, não tinha doze anos, tinha dezassete, não solucei, antes incitei a que ele mesmo olhasse para o fio da faca Sandokan e se calasse para sempre. Hoje, é um homem bom. Faz mandados, transporta caixotes às costas. (Ibidem, p. 49)
\end{abstract}

A tentativa de suavizar a sua culpa no assassinato cruel da irmã Alberta presente no seu discurso na forma de repetições frequentes acerca de ser um bom homem pode ser compreendida à luz do que é ressaltado por Bakhtin em sua obra Problemas da poética de Dostoiévski:

Podemos definir descritivamente todos os fenômenos por nós examinados da seguinte maneira: na autoconsciência do herói penetrou a consciência que o outro tem dele, na auto-enunciação do herói está 
lançada a palavra do outro sobre ele; a consciência do outro e a palavra do outro suscitam fenômenos específicos, que determinam a evolução temática da consciência de si mesmo, as cisões, evasivas, protestos do herói, por um lado, e o discurso do herói com intermitências acentuais, fraturas sintáticas, repetições, ressalvas e prolixidade, por outro (BAKHTIN, 2002, p. 210).

O medo como motivação do narrador fica evidente quando ele conta que, por ser perseguido pelo espectro ele só teria duas opções: vender tudo que possuía na sua terra e fugir ou contar tudo que havia acontecido há vinte e dois anos, e ele havia escolhido a primeira opção. Não há intenção real de se redimir. Ele só quer deixar de ser atormentado pelo espectro. Espectro este que confessa depois ser o único a ver:

Confirmo até agora, que eu saiba, só à minha pessoa aconteceu. Sim, é um segredo só meu. Agora é seu também, a pessoa dos aeroportos a quem contei a coisa má. Desculpe, aqui e ali ter distorcido a verdade da coisa má. Achei que seria mais difuso, menos grave, se a aparição fosse colectiva e pública. Uma aparição que aparece a muitos não aparece a ninguém. Uma comunidade é uma realidade humana, mas não é alguém. Compreendo. Não importa, confirmo. Não omito nem minto. Cumpro a minha palavra. (Ibidem, p. 48)

É só ao se encontrar em situação de overbooking que ele percebe que não terá como fugir: mesmo num distante hotel fornecido pelo aeroporto ainda é perseguido pelo espectro. Assim como há vinte dois anos não incitou o assassinato de uma freira porque não havia espaço suficiente em seu carro, agora era assombrado em um hotel por não ter espaço suficiente no avião para fugir do seu passado. Neste ponto, as duas histórias do conto se encontram. A narrativa fantástica do fantasma de uma freira que assombra e entra pelo peito e a narrativa que pode ser lida à luz da estética da crueldade, que apresenta "a realidade dolorosa e inelutável" (GOMES, 2004, p. 152) se convertem em experiências de um homem que foge. Francisco de Kimbalina decide voltar para sua terra porque tem medo de continuar a ser perseguido já que o espectro é resultado da sua culpa. Segundo Chauí, vivemos sob a

cultura do medo, há de ser também cultura da culpa. Iniciando-se como inimigo externo, o mal insinua-se, sorrateiro, na interioridade do espírito. O pecado, tentação demoníaca, já não precisa de figuras visíveis, nossos devaneios, sonhos e mais secretos desejos cindem nosso ser e o mal chama-se apenas paixão da alma. Emprestamos nosso corpo e nosso espírito para que o diabo seja, restando-nos o medo de nós mesmos. O inferno somos nós (1987, p. 41). 
Portanto, à Francisco não há a possibilidade da fuga. É dentro dele que se esconde a culpa. Seu corpo e seu espírito foi 'emprestado ao diabo' e tudo que Ihe sobrou foi o medo.

\section{REFERÊNCIAS BIBLIOGRÁFICAS}

BAKHTIN, Mikhail. Problemas da poética de Dostoiévski. $3^{\text {a }}$ ed. Tradução: Paulo Bezerra. Rio de Janeiro: Forense Universitária, 2002.

BOURDIEU, Pierre. "Capítulo 1: Uma imagem ampliada". In: $A$ dominação masculina. $2^{\underline{a}}$ ed. Tradução: Maria Helena Kühner. Rio de Janeiro: Bertrand Brasil, 2002.

CHAUÍ, Marilena. "Sobre o medo". In.: NOVAES, Adauto. (Org.) Os sentidos da paixão. São Paulo: Companhia das Letras, 1987.

CHEVALIER, Jean; GHEERBRANT, Alan. "Couteau", "Nudité". Dictionnaire des symboles. $11^{\mathrm{a}}$ ed. Paris: Éditions Robert Laffont et Éditions Jupiter, 1990.

CORTÁZAR, Julio. "Alguns aspectos do conto". In: Valise de cronópio. $2^{\mathrm{a}}$ ed. São Paulo: Perspectiva, 2006.

DOSTOIÉVSKI. Crime e castigo. $3^{\mathrm{a}}$ ed. Tradução: Ivan Petrovitch e Irina Wisnik Ribeiro. São Paulo: Martin Claret, 2002.

GOMES, Renato Cordeiro. "Narrativa e paroxismo: será possível um pouco de sangue verdadeiro para manifestar a crueldade?". In: DIAS, Ângela Maria; GLENADEL, Paula (Org.). Estéticas da crueldade. Rio de Janeiro: Atlântica, 2004.

JORGE, Lídia. O amor em Lobito Bay. Contos. Lisboa: Dom Quixote, 2016.

PIGLIA, Ricardo. "Teses sobre o conto". In: Formas Breves. Tradução: José Marcos Mariani de Macedo. São Paulo: Companhia das Letras, 2004.

ROAS, David. "O fantástico como problema de linguagem". In: ALVES, Maria Cláudia Rodrigues et al. (Org.) Pelas veredas do fantástico, do mítico e do maravilhoso. $1^{1}$ ed. São Paulo, Cultura Acadêmica, 2013.

SARLO, Beatriz. Tempo passado: cultura da memória e guinada subjetiva. São Paulo: Companhia das Letras; Minas Gerais: UFMG: 2007.

TODOROV, Tzvetan. "Os fantasmas de Henry James". In: Poética da Prosa. Tradução: Claudia Berliner. São Paulo: Martins Fontes, 2003. 